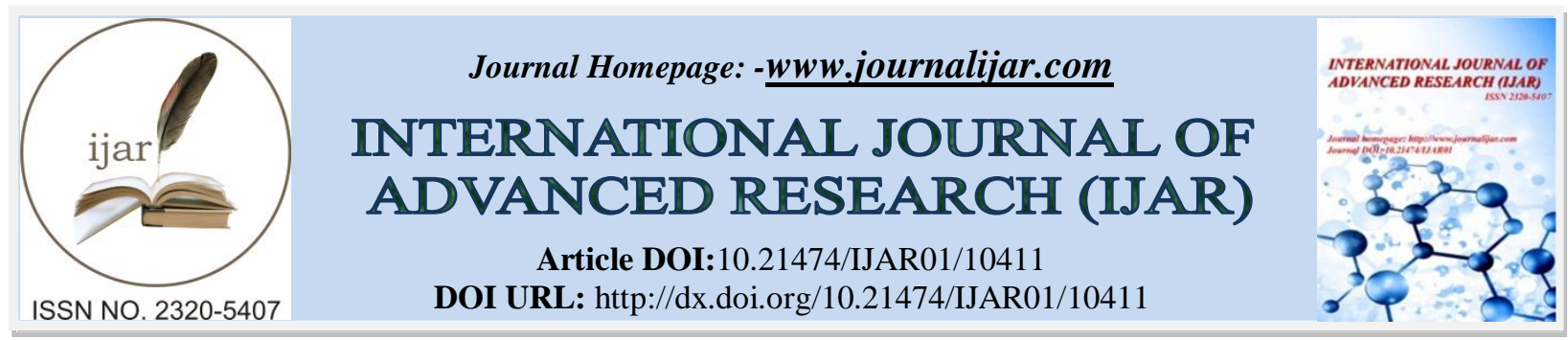

RESEARCH ARTICLE

\title{
MYCOLOGICAL PROFILE OF FUNGAL RHINOSINUSITIS - A STUDY FROM A TERTIARY CARE HOSPITAL IN MAHARASHTRA
}

\section{Dr. Smita S. Kulkarni ${ }^{1}$, Dr. M.V. Mulay ${ }^{2}$ and Dr. H. S. Ghogare ${ }^{3}$}

1. Assistant professor, Department of Microbiology, MGM Medical College \& Hospital, Aurangabad, Maharashtra.

2. Professor \& Head, Department of Microbiology, MGM Medical College \& Hospital, Aurangabad, Maharashtra.

3. Associate Professor, Department of Microbiology, MGM Medical College \& Hospital, Aurangabad, Maharashtra.

\section{Manuscript Info}

Manuscript History

Received: 30 November 2019

Final Accepted: 31 December 2019

Published: January 2020

Key words:-

Dextrose Agar, Mucor, Aspergillus

Flavus
Fungal Rhinosinusitis, Sabouraud's

\begin{abstract}
A prospective observational study was conducted for two years in a tertiary care hospital to evaluate the mycological profile of clinically suspected patients of fungal rhinosinusitis. 52 samples were processed during the study period. Samples were subjected to direct microscopy by $\mathrm{KOH}$ mount and were inoculated on Sabouraud's dextrose agar. Identification of fungi was done as per standard protocol. Specimens collected were nasal crust/exudates, nasal swabs, biopsy from nasal and maxillary sinus mucosa. Out of 52 samples, fungal elements were seen in 31(59.61\%) samples on $\mathrm{KOH}$ mount and fungal growth was obtained in $22(42.30 \%)$ samples. Mucor was the most common isolate (34.78\%) in this study followed by Aspergillus flavus (21.73\%). Diabetes mellitus was found to be the most common (55.79\%) predisposing factor in our study. Early diagnosis of fungal rhinosinusitis is very important due to angioinvasive nature of the fungi which may lead to more serious complications if not treated.
\end{abstract}

Copy Right, IJAR, 2020,. All rights reserved.

\section{Introduction:-}

Rhinosinusitis is defined as an inflammation of nasal and paranasal sinus mucosa which is associated with mucosal alterations and ranging from thickening to gross nasal polyp formation. ${ }^{1}$ Fungi are common cause of rhinosinusitis and incidence of such infections is increasing day by day. Variety of fungi cause rhinosinusitis including the Zygomycets, Aspergillus species and dematiaceous fungi. ${ }^{2}$ Fungal rhinosinusitis occurs in both acute and chronic forms and it also leads to invasive form. Fungal rhinosinusitis is frequently seen in immunocompromised and diabetic patients, however it has also been reported in immunocompetent individuals. Fungal rhinosinusitis leads to high morbidity and even may cause high mortality especially in patients having acute invasive disease. ${ }^{3}$ The various complications of fungal rhinosinusitis are orbital and intracranial manifestations. ${ }^{4}$ This study was undertaken to isolate and identify the fungi causing rhinosinusitis.

\section{Aims and Objectives:-}

1. To study various predisposing factors associated with fungal rhinosinusitis

2. To study the fungal etiological agents among the clinically suspected patients of fungal rhinosinusitis.

\section{Corresponding Author:- Dr. M.V. Mulay}

Address:- Professor \& Head, Department of Microbiology, MGM Medical College \& Hospital, 


\section{Inclusion criteria:-}

Clinically suspected cases of fungal rhinosinusitis of all age groups

\section{Exclusion criteria:-}

Patients on antifungal treatment

\section{Material and Methods:-}

This prospective observational study was conducted in MGM Medical College \& Hospital, Aurangabad, Maharashtra, for a period of two years from Jan 2018 to December 2019. A total of 52 specimens were processed in the Mycology section of the Microbiology department. All the specimens were collected from patients attending the ENT department of the same hospital. The relevant clinical details of the patients including comorbid conditions were recorded.

\section{Specimens included:-}

The specimens received in the laboratory for diagnosis of fungal rhinosinusitis were nasal swabs collected during nasal endoscopy, nasal crusts, allergic mucin, tissue biopsy from nasal cavity, tissue biopsy from sinus mucosa. All specimens were received in sterile containers.

\section{Potassium hydroxide mount (KOH):-}

Direct microscopic examination of specimens was done by potassium hydroxide (KOH) mount preparation. If specimen was not properly dissolved, it was kept for one hour with addition of DMSO and re-examined ${ }^{4}$.

\section{Fungal Culture ${ }^{4}:-$}

The samples were inoculated on two tubes of Sabourauds dextrose agar with antibiotics (chloramphenicol) and without cyclohexamide. One tube of SDA was incubated at room temperature and other tube was incubated at $37^{0} \mathrm{C}$. Cultures were examined daily during first week and twice a week thereafter for further three weeks. If no growth observed at the end of four weeks then cultures were considered negative for fungal growth. The culture slopes showing fungal growth were examined for colony characters like rate of growth of colony, texture of colony, surface of colony, colour of colony and pigment production on the reverse side of agar slope.

Gram stain was done on smooth, moist and pasty colonies. Cultures showing gram positive budding yeast cells were further subjected to Germ tube test. Depending upon colony morphology and microscopic appearance the fungal isolates were identified.

Lactophenol cotton blue preparation ${ }^{5,6}:-$

Lactophenol cotton blue preparation was done to study morphological features of mycelial fungal growth.

A small drop of lactophenol cotton blue was placed on microscope slide. Using sterile technique, a small amount of mycelium from the culture was removed with inoculation needle and placed in the drop of lactophenol. With the help of teasing needles the mycelium was gently teased. Coverslip was placed over it and examined under microscope.

Preparation of a slide culture ${ }^{6}:-$

A bent glass rod was placed at the bottom of a sterile plate. A microscope slide was placed on the glass rod. 8-10 ml sterile water was added to the piece of filter paper kept at the bottom of petri plate. Using a sterile scalpel, $1 \mathrm{~cm}$ square of corn meal agar medium was cut and placed near the centre of the microscope slide. Fungal strain was inoculated at four sides of agar block with inoculating needle. A sterile coverslip was applied to the inoculated block. The lid of the petri plate was replaced and incubated at $30^{\circ} \mathrm{C}$ in BOD incubator. When growth appeared at the upper edge of square, coverslip was removed. A drop of lactophenol cotton blue was placed on a new microscope slide and coverslip from block was placed on the drop with growth side down. The slide culture preparation was studied microscopically for morphological details.

Taking in account observations of direct microscopy, cultural characteristics and lactophenol cotton blue preparations of fungal growth, fungi were identified. 


\section{Results:-}

Out of the 52 cases we studied, 34(65.30\%) were males and $18(34.61 \%)$ were females. The male to female ratio was 1.8:1. The age distribution of cases were 21-30year age group 05 (9.61\%)cases, 31-40 years age group 13 (25\%) cases, 41-50 years age group $19(36.53 \%)$ cases, 51-60 years age group $08(15.38 \%)$ cases, $61-70$ years age group $04(7.69 \%)$ cases, $71-80$ years age group $02(3.84 \%)$ cases. Majority of cases were seen in age group of 41-50 years. (Table1)

The most common clinical presentation in our study was nasal discharge (69.23\%) followed by nasal blockage $(53.84 \%)$. Other symptoms were difficulty in breathing (36.53\%), headache $(26.92 \%)$ and ocular swelling $(21.15 \%)$. (Table 2)

In this study the most common predisposing factor was diabetes mellitus found in $55.79 \%$ of total cases studied. Other factors predisposing to fungal rhinosinusitis were nasal allergy (30.73\%), deviated nasal septum (9.63\%) and dental caries (3.84\%). (Table 3)

Out of 52 samples, 31 samples were found $\mathrm{KOH}$ positive (Fig1) and remaining 21 were found $\mathrm{KOH}$ negative. Culture positivity was seen in 22 samples while there is no growth in 30 samples. 18 samples were found positive by both $\mathrm{KOH}$ and culture while 17 samples were negative for both $\mathrm{KOH}$ and culture. (Table 4)

Out of 22 samples that showed fungal growth, the most common isolate was Mucor species (31.81\%) (Fig 2). Aspergillus flavus was the second most common isolate (22.72\%). Other fungal species isolated were Rhizopus (18.18\%) (Fig 3), Aspergillus fumigatus (13.63\%), Aspergillus niger (9.09\%). Candida albicans was isolated in one sample (4.54\%). (Table 5)

Out of 52 samples received in Microbiology department, 12 nasal crusts/exudates, 5 nasal swabs, 3 nasal biopsies and 2 maxillary sinus biopsy showed fungal growth.

\begin{tabular}{|l|l|l|}
\hline Age groups (in years) & No. of patients $(\mathbf{n = 5 2})$ & Percentage \% \\
\hline $0-10$ & 00 & 00 \\
\hline $11-20$ & 00 & 00 \\
\hline $21-30$ & 05 & 9.61 \\
\hline $31-40$ & 13 & 25.00 \\
\hline $41-50$ & 19 & 36.53 \\
\hline $51-60$ & 08 & 15.38 \\
\hline $61-70$ & 04 & 7.69 \\
\hline $71-80$ & 03 & 5.79 \\
\hline
\end{tabular}

Table 1:- Age-wise distribution of fungal rhinosinusitis.

\begin{tabular}{|l|l|l|}
\hline Clinical presentation & No. of patients & Percentage \% \\
\hline Nasal discharge & 36 & 69.23 \\
\hline Nasal blockage & 28 & 53.84 \\
\hline Difficulty in breathing & 19 & 36.53 \\
\hline Headache & 14 & 26.92 \\
\hline Orbital swelling/ocular symptoms & 11 & 21.15 \\
\hline
\end{tabular}

Table 2:- Clinical presentation of patients.

\begin{tabular}{|l|l|l|}
\hline Predisposing factor & Total no of patients $(\mathbf{n}=\mathbf{5 2})$ & Percentage \% \\
\hline Diabetes mellitus & 29 & 55.79 \\
\hline Nasal allergy & 16 & 30.76 \\
\hline Deviated nasal septum & 05 & 9.61 \\
\hline Dental caries & 02 & 3.84 \\
\hline
\end{tabular}

Table 3:- Predisposing factors.

\begin{tabular}{|l|l|l|l|}
\hline & KOH positive & KOH negative & Total \\
\hline Culture positive & 18 & 04 & 22 \\
\hline
\end{tabular}




\begin{tabular}{|l|l|l|l|}
\hline Culture negative & 13 & 17 & 30 \\
\hline Total & 31 & 21 & 52 \\
\hline
\end{tabular}

Table 4:- Microscopy and culture positivity of specimens.

\begin{tabular}{|l|l|l|}
\hline Isolated fungal species & Number of isolates $(\mathbf{n = 2 2})$ & Percentage $\%$ \\
\hline Mucor species & 07 & 31.81 \\
\hline Aspergillus flavus & 05 & 22.72 \\
\hline Rhizopus species & 04 & 18.18 \\
\hline Aspergillus fumigatus & 03 & 13.63 \\
\hline Aspergillus niger & 02 & 9.09 \\
\hline Candida albicans & 01 & 4.54 \\
\hline Total & 22 & 100 \\
\hline
\end{tabular}

Table 5:- Details of fungal species isolated.

\begin{tabular}{|l|l|l|}
\hline Specimen & Total & Fungal isolates \\
\hline Exudates/crusts from nose & 29 & $12(41.37 \%)$ \\
\hline Nasal swabs & 14 & $05(35.71 \%)$ \\
\hline Biopsy from nasal cavity & 05 & $03(60.00 \%)$ \\
\hline $\begin{array}{l}\text { Biopsy /pus from } \\
\text { maxillary sinus cavity }\end{array}$ & 04 & $02(50.00 \%)$ \\
\hline
\end{tabular}

Table 6:- Specimens with culture positivity.

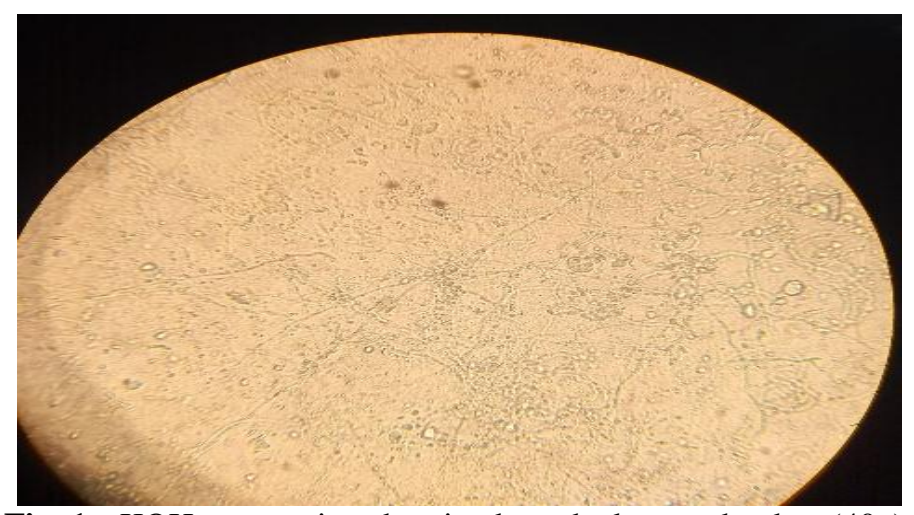

Fig. 1:- KOH preparation showing branched septet hyphae (40x).

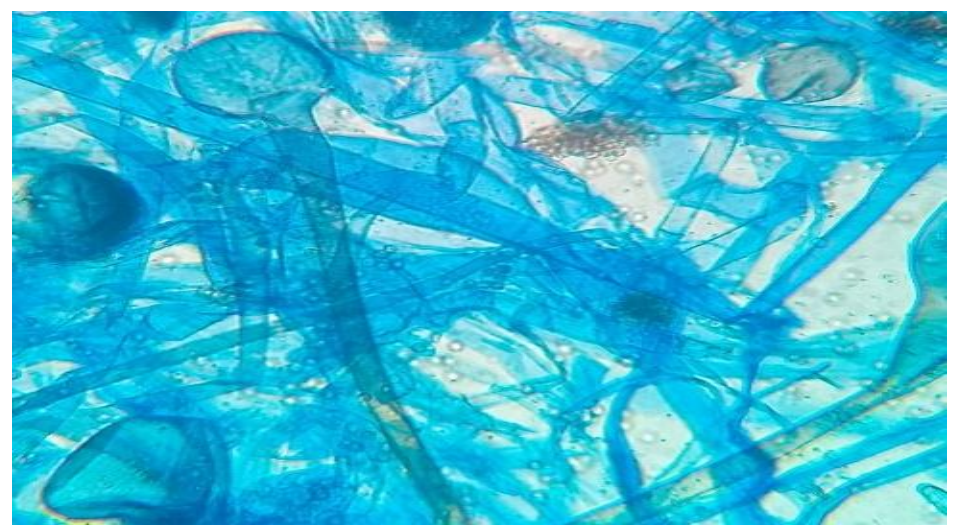

Fig. 2:- lactophenol cotton blue preparation of Mucor (40x). 


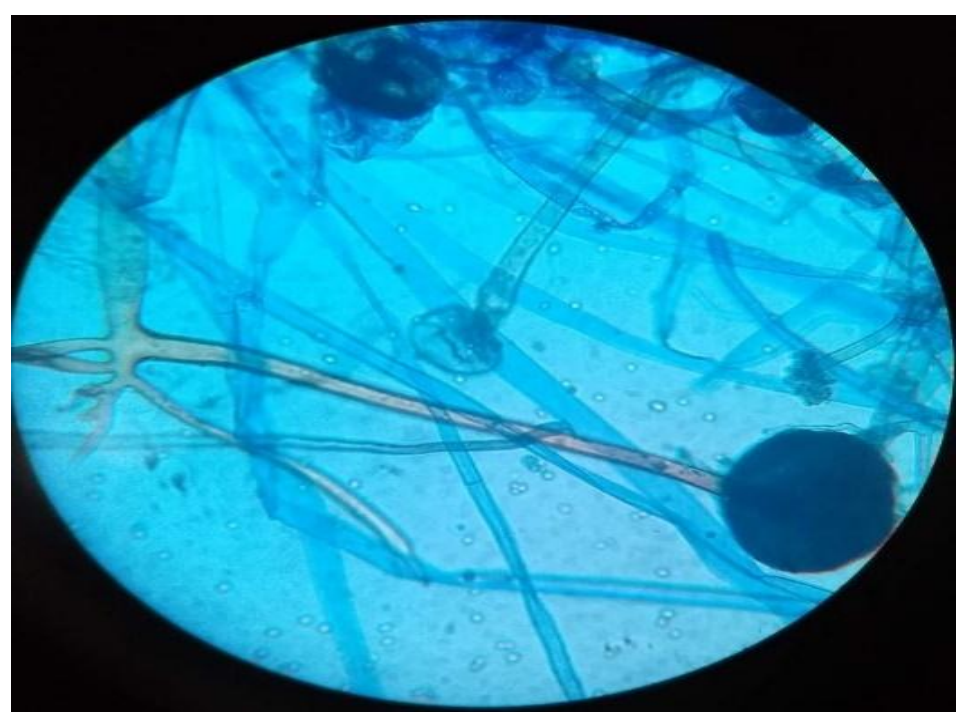

Fig 3:- lactophenol cotton blue preparation of Rhizopus species (40x).

\section{Discussion:-}

The present study was conducted to study the fungal etiological agents among the clinically suspected patients of fungal rhinosinusitis. Patients from all the age groups and both the sexes were included in the study.

In this study fungal rhinosinusitis was predominantly seen in male population $(65.30 \%)$ with male to female ratio of 1.8:1. Male predominance was also seen in the study conducted by Shivani et al $(1.4: 1)^{7}$ and Prateek et al $(1.3: 1)^{8}$. In contrast Dufour et $\mathrm{al}^{9}$ showed female predominance in their study.

In this study the age of patients ranged from 21 to 80 years. Our study revealed that incidence of rhinosinusitis is increasing with advancing age and it was found to be commonest in the age group of 41-50 years with $36.53 \%$ cases. High prevalence of fungal rhinosinusitis during the fourth decade was found in another study conducted by Anushuya $\mathrm{G}$ et $\mathrm{al}^{10}$.

In this study the most common predisposing factor was diabetes mellitus, found in $(55.79 \%)$ of cases. In the study conducted by Mohapatra et $\mathrm{al}^{12}$, they found hyperglycaemia in $44.8 \%$ of cases. Michael et al $^{2}$ observed uncontrolled diabetes in $38.8 \%$ of cases of invasive fungal sinusitis. The patients with diabetes mellitus are more prone to fungal infections. One of the causes of increased susceptibility to infections in diabetic patients is impaired leukocyte function. Shivani et $\mathrm{al}^{7}$ observed nasal allergy (19.44\%) as the most common risk factor in their study.

In the present study, $\mathrm{KOH}$ positivity was $59.61 \%$ and fungal culture positivity was $42.30 \%$. Out of these $34.61 \%$ were positive by both $\mathrm{KOH}$ examination and culture. $13(25 \%)$ samples were $\mathrm{KOH}$ positive and culture negative. This could be due to antifungal therapy initiated before sample collection or inadequate samples. Suman Lata Virdi ${ }^{13}$ et al also found $\mathrm{KOH}$ positivity $(36.8 \%)$ more than cultural positivity $(26.3 \%)$ in their study.

In present study the most common causative fungal agent was found to be Mucor species consisting of $31.81 \%$ cases followed by Aspergilius flavus consisting of $22.72 \%$ cases. Similar findings were seen in the study conducted by Anushuya $G$ et $\mathrm{al}^{10}$. In contrast to this, Shivani et $\mathrm{al}^{7}$, Chakrabarti A et $\mathrm{al}^{11}$ and Udayasri B et al ${ }^{14}$ reported Aspergilius flavus as the most common fungal causative agent in their studies. Other fungal isolates were Rhizopus species, Aspergillus fumigatus, Aspergillus niger and Candida albicans.

\section{Conclusion:-}

Fungal rhinosinusitis affects day to day functioning of patients and causes significant morbidity. Diabetes mellitus $(55.79 \%)$ was found to be most common predisposing factor. The common fungal agent causing rhinosinusitis in our study was Mucor species (31.81\%) followed by Aspergillus flavus (22.72\%). Due to highly invasive nature of both mucormycosis and aspergillosis, prompt diagnosis and early treatment of fungal rhinosinusitis is essential. Hence culture directed therapy is gold standard for the management of rhinosinusitis. 


\section{Acknowledgement:-}

We are thankful to the ethical committee for permitting us to conduct this study.

\section{Conflict of interest:-}

None

\section{Financial assistance:-}

None

\section{References:-}

1. Spector SL, Bernstein IL, Li JT, Berger WE, Kaliner MA, et al. Parameters for the diagnosis and management of sinusitis. J Allergy Clin Immunol 1998; 102 (6pt2):S107-44.

2. Rajiv. C. Michael, Joy S Michael, Ruth H Ashbee, Mary Mathews. Mycological profile of fungal sinusitis: An audit of specimens over a 7 year period in a tertiary care hospital in Tamilnadu. Indian Journal of Pathology and Microbiology. 2008; 51(4)493-6.

3. DeShazo RD, Chapin K, Swain RE. Fungal sinusitis. N Engl J Med 1997; 337:254-9.

4. Chander J. Dermatophytosis in: Textbook of Medical Mycology. $3^{\text {rd }}$ ed. New Delhi. Mehta; 2009; p122-46.

5. Winn WC, Allen SD, Janda WM, Koneman EW, Procop GW, Schreckenberger PC, Woods GL, Mycology in : Koneman's Color Atlas and Textbook of Diagnostic Microbiology. $6^{\text {th }}$ ed. Lippincott Williams \& Wilkins.2006; p 1162

6. Errol Reiss, H. Jean Shadomy, G. Marshall Lyon. Laboratoty Diagnostic Methods in Medical Mycology in: fundamental Medical Microbiology. $1^{\text {st }}$ ed. Jhon Wiley \& Sons, Inc., Hoboken, New Jersey. 2012; p 31-33.

7. Shivani, Bimla Devi, Karan Sharma, Pushpa devi, Rupali, Gagan Deep. Mycological profile of fungal rhinosinusitis in a tertiary care hospital. Int J Contemporary Med Research. 2016; 3(4)1026-1028.

8. Prateek S, Banerjee G, Gupta P, Singh M, Goel MM, Verma V. Fungal rhinosinusitis: A prospective study in a University hospital of Uttar Pradesh. Indian Journal of Med Microbiolopgy. 2013; 31:266-9.

9. Dufour X, Kauffmann-Lacroix C, Ferrie JC, Goujon JM, Rodier MH, Klossek, JM. Pranasal sinus fungal ball, epidemiology, clinical features and diagnosis. A retrospective analysis of 173 cases from a single medical centre in France, 1989-2002. Med Mycol2006; 44:61-7.

10. Anushuya G, Aja Chandramohan, Ponnusamy Karkuzhali, Manickam Saraswathi. Fungal rhinosinusitis: A clinicomorohological study in a tertiary institute. Indian J Pathology Oncology.2019; 6(1):35-38.

11. Chakrabarti A, Sharma SC. Paranasal sinus mycoses. Indian J Chest Dis Allied Sci. 2000; 42:293-04.

12. Mohapatra S, M Jain, I Xess. Spectrum of Zygomycosis in North India: An institutional experience. Indian J Medical Microbiology.2010; 28(3):217-230.

13. Suman Lata Virdi, Gursimran Kaur Mohi. Clinico Mycological profile of allergic fungal rhinosinusitis (AFRS) on a tertiary care hospital. Ann Int Med Den Res. 2017; 3(3):MB01-MB06.

14. Udayasri B, T. Radhakumari. Microbial etiology of chronic sinusitis. J. Dental and Medical Sci. 2016; 15:118124. 